

\title{
Recriações à venda? Sophie Taeuber-Arp e o caso da terceira Bienal de São Paulo
}

\author{
Recreations for sale? Sophie Taeuber-Arp and the case of the third Bienal \\ de São Paulo
}

Dr. Marcelo Mari *

\begin{abstract}
Resumo
Depois de receber prêmio de aquisição na I Bienal de São Paulo, Sophie Taeuber-Arp ganhou grande exposição em sua homenagem na III Bienal, de 1955. Para isso, a Embaixada Suiça organizou, conjuntamente com Jean Arp, a exposição das obras dessa artista, que morrera prematuramente, mas que tinha deixado contribuição seminal para a arte de tendência construtiva. $O$ fato é que a sala especial de Taeuber-Arp na Bienal foi e ainda é a exposição mais completa de suas obras. Na sala expositiva da artista havia, além de pinturas, fotografias, maquete e relevos. Aquilo que não poderia ser trazido foi copiado em fotografia ou mesmo em pintura. Não havendo material explicativo sobre a origem de cada obra, de que se tratava de fotografia ou até mesmo réplica de trabalhos desaparecidos, ou inacessíveis, o público que visitava a Bienal poderia ser confundido pela impressão de que tudo ali fora realmente produzido pela artista suiç̧a, o que não era verdade.
\end{abstract}

\section{Palavras-chave}

Sophie Taeuber-Arp. Recriações ou réplicas. Bienal de São Paulo. Mercado de Arte.

\begin{abstract}
After receiving an acquisition award at the first Bienal de São Paulo, Sophie Taeuber-Arp had a great exhibition in her honor at the third Biennial of 1955. To this end, the Swiss Embassy organized, together with Jean Arp, an exhibition of the artist's works, who had died prematurely but had made a seminal contribution to the constructive tendency. The fact is that Taeuber-Arp's special room at the Bienal is the most complete exhibition of her works so far. In the artist's exhibition room there were paintings, photographs, model and reliefs. What could not be brought was copied into photography or even painting. If there were no explanatory material on the origin of each of the works, that it was photographs or even replicas of missing or inaccessible works, the public visiting the Biennale could be confused by the impression that everything there had actually been produced by the Swiss artist, which was not true.
\end{abstract}

\section{Keywords}

Sophie Taeuber-Arp. Recriations or Replicas. Bienal de São Paulo. Art Market. 
Em 27 de maio de 1958, Mário Pedrosa escreveu artigo sobre seu encontro com Jean Arp na França. Não era um encontro casual. Pedrosa estreitava contato com membros do famoso grupo de artistas que militou em prol da arte moderna no período da Segunda Guerra e frequentou zonas livres da ocupação Alemã, e especialmente a cidade de Grasse, lugar controlado pela resistência francesa. Esse grupo foi denominado de Grupo de Grasse e teve como seus integrantes Sonia Delaunay, Alberto Magnelli, Jean Arp e Sophie Taeuber-Arp. Embora viessem de experiências anteriores distintas, como é o caso do realismo onírico de Magnelli ou do dadaísmo do casal Arp, todos eles centraram pesquisa no abstracionismo.

O interesse de Pedrosa por Arp passava pelo contato que mantinha com outro artista da resistência, Magnelli, muito apreciado no Brasil, principalmente depois da mostra e da aquisição de sua obra através de prêmio da Bienal. Foi justamente após contato feito por Magnelli com o velho amigo Arp, que Pedrosa foi recebido na residência dele em Meudon. $O$ interesse pela produção de Arp mostra o quanto Pedrosa era aberto às expressões da arte moderna sem o sectarismo dogmático de parte do concretismo brasileiro, fechado em soluções preestabelecidas de manifestação artística, como a realização de jogos formais na aplicação de leis da visualidade. A obra de Arp era tudo menos isso, ainda mais se levarmos em conta suas pregressas experiências dadaístas.

Dos artistas do Grupo de Grasse, Jean Arp (também conhecido por Hans Arp, por conta de sua origem Franco-alemã) foi sem dúvida o que obteve maior sucesso. Isso se explica em parte pelo fato de ele ter seu nome inscrito na vanguarda histórica do dadaísmo. Artistas como ele passaram o período de entreguerras e o da Segunda Guerra lutando contra as circunstâncias em nada favoráveis à arte moderna. Muitos artistas padeceram por acreditarem na arte tanto como meio de afirmação de seus projetos individuais de vida quanto como manifestação transgressiva das coisas estabelecidas em um mundo burguês cada vez mais em aberta crise de consciência. Jean Arp não foi diferente; fez de sua arte uma luta contra o fascismo, em que pese a ausência propositada de conteúdo político explícito em seu trabalho artístico. 0 artigo de Pedrosa descreve justamente 0 encontro com essa geração vanguardista europeia de artistas. Uma geração em extinção, com a subordinação insistente e cada vez maior da arte à institucionalidade e à consolidação do novo mercado de arte internacional.

Não bastasse esse mergulho na densidade geracional desses artistas vanguardistas da Europa, o artigo de Pedrosa traz descrição vívida de Jean Arp, de sua relação com Sophie Taeuber-Arp e das obras da falecida esposa. Afinal, Taeuber-Arp foi pioneira do concretismo no mundo e, a partir da III Bienal de São Paulo, tornou-se forte referência para críticos de arte e jovens artistas brasileiros. Eis a descrição do ambiente que encontrou na casa de Jean Arp, que na ocasião residia com Marguerite Hagenbach:

Esperava-me por um telefonema anterior de Magnelli. Abriu-me a porta uma senhora que Ihe faz a vez de secretária. Era uma amiga de infância de Sofia Taeuber-Arp: desta forma, o marido e a amiga comungam, juntos, no culto da memória da grande artista morta. $\mathrm{Na}$ sala em que o escultor atende às visitas as paredes e os cantos estão tomados indistintamente com obras de Arp e obras de Sofia. E ele faz questão, depois, de nos levar ao seu quarto para nos mostrar as últimas telas de Sofia que o adornam. Na parede da cabeceira, está um dos mais belos e finos quadros daquela extraordinária mulher. Arp não perdoa aos organizadores dos Cinquenta Anos de Arte Moderna, na Exposição Internacional de Bruxelas, a ausência de Sofia Taeuber-Arp. Nem ele, nem nós. É realmente um escândalo aquela omissão, quando as salas estão cheias de artistas de segunda ordem. Representando, aliás, a Suiça lá está imensa tela de Hodler, que hoje é apenas uma figura histórica. Ao passo que Sofia ainda hoje vive, e foi um dos portabandeiras mais representativos da arte abstrata e da arte concreta. Sua lição vai ficar (Pedrosa, 1958: 06). 
No ano de 1959, estimulado pela disputa entre concretos paulistas e cariocas, o crítico e poeta Ferreira Gullar escreveria um pequeno artigo no Suplemento Dominical do Jornal do Brasil, intitulado "Arte concreta no Brasil", para explicar o surgimento da arte concreta e suas primeiras manifestações por aqui. Para isso, o crítico traz à baila a importância da Bienal para contato não somente com as manifestações mais renovadas da arte moderna como também com seus precursores. Entre os precursores, Gullar escolheu aqueles que foram responsáveis pela produção e difusão da arte concreta e, entre eles, Sophie Taeuber-Arp:

\begin{abstract}
A I Bienal do Museu de Arte Moderna de São Paulo, inaugurada em outubro de 1951, viria dar um impulso decisivo ao movimento nascente, proporcionando aos artistas e críticos brasileiros o conhecimento das obras abstratas ou concretas de Sofia Taeuber- Arp, Max Bill, Richard P. Lohse, Walter Bodmer, Oskar Dalvit, Leo Leuppi e outros, que integravam a representação da Suíça. $O$ Grande Prêmio de Escultura do certame, concedido pelo júri internacional à Unidade Tripartida, de Bill, assinalava a primeira grande vitória internacional da arte concreta numa exposição dessa natureza e chamava a atenção para este artista, cuja obra e cujas ideias iriam, a partir de então, influir profundamente no curso da arte brasileira (Gullar, 1985: 227-228).
\end{abstract}

Tratava-se de enfatizar a importância da arte concreta para a produção contemporânea brasileira. Tanto Ferreira Gullar como Mário Pedrosa tornaram-se naquele momento os críticos-militantes da tendência construtiva, em oposição ao velho realismo social nas artes brasileiras, que estetizava a miséria, e também ao abstracionismo lírico, ao expressionismo abstrato, aos informalismos de toda sorte de arte centrada no subjetivismo poético. Foi justamente na consolidação da tendência construtiva na arte e da arte concreta no Brasil que Taeuber-Arp foi incluída nas coleções brasileiras e depois teve sua obra contemplada na Bienal com sala especial.

De fato, a Bienal de São Paulo serviu como fonte de atualização para jovens artistas que podiam ver nas suas salas expositivas um conjunto da produção moderna e de outrora que dialogava com a problemática hodierna. A Bienal foi esse canal de contato com a produção de arte moderna mundial, não somente para o Brasil, mas para a América Latina. Entre os artistas sediados no Brasil que também reconheceram a importância da exposição das obras de Taeuber-Arp na Bienal, citamos aqui Maria Bonomi.

Em 1955, ocasião da III Bienal, Bonomi comentou o impacto da produção de Taeuber-Arp para a arte brasileira e para o concretismo no Brasil. Embora ela residisse em São Paulo e não tivesse travado vínculo com o concretismo carioca, sua visão sobre a contribuição das obras de Taeuber-Arp para pensar a produção local é indicativa de como as lições da artista suiça serviram para realizar a crítica de uma posição mais dogmática da arte concreta e forneceram novos caminhos, mais robustos, para a produção artística amparada nas lições de simplicidade e estrutura da construção formal. A impressão de Bonomi era de que a postura pragmática de certos artistas concretos brasileiros, por intentar aproximação entre arte e indústria, incidia em velhos erros já ocorridos na arte europeia. Isso porque depois da guerra a aproximação entre forma artística e indústria de consumo era vista como um perigo utilitarista.

Maria Bonomi fez a análise para a revista italiana / 4 soli sobre as novidades e correntes dominantes na arte brasileira a partir da experiência da III Bienal de São Paulo. Os comentários de Bonomi tentam situar diferença entre as experiências visuais feitas por Taeuber-Arp e o concretismo brasileiro (talvez latino-americano) que teria se dogmatizado e forçado a experiência artística para legitimação de valores extra-artísticos, principalmente pela utilização mecânica de soluções gestálticas. Esses comentários incidem na motivação principal das diferenças e da disputa entre concretos paulistas e cariocas. 0 ano 
de 1955, marca justamente a percepção da diferença entre os dois grupos, que resultou poucos anos depois na formação do neoconcretismo carioca. Diz Bonomi:

Os dois grandes mistérios agora descobertos na III Bienal de São Paulo são Sophie Taeuber-Arp e G. Sutherland. Duas tendências divergentes, mas igualmente potentes e que nos impõem meditações justamente por sua força na diversidade. Sophie Arp, com obras que vão de 1920 até 1942, é talvez entre as presenças mais importantes de ontem, aquela que deixará traços mais profundos. Se acha nela a arte concreta no mais alto grau de pureza e justeza em todos os tempos. Quando me sentia saturada das várias 'formas' angustiadas que caracterizam a pesquisa contemporânea, achava nela aquela profunda simplicidade que, nos remetendo a um ponto de partida, nos ensina a andar adiante. Entre as formas que me colocavam em repouso devo infelizmente citar tantos concretistas contemporâneos (talvez de amanhã?) que não só não viveram os processos conscientes de Mondrian, de Sophie Arp... e outros mestres, mas que se improvisam nesta enganosa corrente acreditando (simplesmente por escolher e organizar formas agradáveis) terem chegado ao fim da longa via da pintura, onde agora poderão sentar-se e profetizar a fusão morfológica da arte com a máquina... que no fim das contas nós mesmos fabricamos. Não sei na Europa, mas aqui é a tendência mais forte (como estamos para trás, não é verdade?). Não creio que o concretismo seja uma solução, mas apenas uma experiência às vezes obrigatória para muitos como é até agora na história da arte. Me dão medo certos visionários atuais que repetem, sem ter compreendido, aquele brilhante diálogo (porém com a morte) de Sophie Taeuber-Arp (Bonomi, 1955: 03-04).

Vista com certo distanciamento, a posição de Maria Bonomi parece se fixar menos no perigo de assimilação da arte pela indústria capitalista em um processo de estetização da arte para o consumo de massa do que na quebra da autonomia formal pelo peso funcionalista. Essa foi a problemática que envolveu inclusive os artistas cariocas, tais como Lygia Clark e Hélio Oiticica. De fato, a obra de Sophie Taeuber-Arp vinha sinalizar talvez que a arte concreta poderia ser mais do que simplesmente um jogo de formas privilegiadas e de aplicação das relações entre forma e fundo. Seus relevos já indicam a possibilidade de se pensar a arte para além das categorias tradicionais, pintura e escultura, e passar a compreender o produto da arte moderna como objeto de arte. 0 objeto assume centralidade na arte. Essa foi sem dúvida uma contribuição da exposição de Taeuber-Arp, em sala especial, na Bienal de São Paulo em 1955.

Todavia, a primeira exposição de obras de arte de Sophie Taeuber-Arp no Brasil foi trazida e organizada pelo Museu de Arte Moderna de São Paulo em 1949. Sob direção de Francisco Matarazzo Sobrinho, que convidou Léon Degand para ser diretor do museu, a exposição foi nomeada Do Figurativo ao Abstracionismo e inaugurada no dia 8 de março daquele ano. Duas obras de Sophie Taeuber-Arp foram ali exibidas. A primeira, intitulada Planos, barras e linhas ondulantes, 1943, óleo sobre papelão, dimensões $57 \times 48 \mathrm{~cm}$, e também Subindo, caindo, aderindo, voando, cerca de 1942, óleo sobre tela, $100 \times 73 \mathrm{~cm}$, ambas as obras faziam parte da coleção Jean Arp, guardadas em sua casa em Meudon, na França. A exposição organizada por Léon Degand em São Paulo e a pequena exposição de Alexander Calder organizada por Mário Pedrosa no Rio de Janeiro são considerados mais explicitamente os primeiros esforços para exibir arte abstrata no Brasil.

Naquele ano de 1949, a exposição, organizada por Degand sob os auspícios do Museu de Arte Moderna de São Paulo, havia sido realizada em edifício moderno no centro de São Paulo. O contexto da relação entre arte abstrata e modernização industrial fora contemplado, porém a exposição parecia inusitada para o gosto brasileiro. Isso porque ainda vigorava aqui uma preferência pela arte de representação realista, atada ainda às velhas classificações de fatura e ao tradicionalismo do gosto. Tudo que se aproximava do aspecto abstrato ou funcionalista perdia aura de atividade artística maior. Porém, 0 abstracionismo nasce com essas características marcantes de buscar fazer parte e constituir um novo 
cotidiano estético para a vida moderna. Como negar isso? Sem dúvida, a aproximação da arte moderna com a grã-finagem patrocinadora marcava um aspecto demasiadamente prejudicial da arte burguesa, que era justamente associá-la com essa esfera de atividade em manifestação idílica contra sobretudo os processos reais de massificação e democratização da forma estética moderna².

Isso não quer dizer que a figuração social não estivesse ali representada como o principal motivo da arte brasileira de derivação estado-novista. 0 que se entrevê no catálogo da exposição organizada por Léon Degand é a disputa de visões de mundo. Esse catálogo fornecia uma amostra do estado das artes visuais no Brasil. $O$ debate sobre arte figurativa e abstração estava se aquecendo e tomaria proporções decisivas no momento da inauguração da I Bienal de São Paulo. Além das forças estarem divididas, muitas vezes elas ocupavam os mesmos espaços culturais e institucionais. É o caso de Milliet e Degand. Sergio Milliet também foi convidado por Degand a escrever no catálogo da exposição de 1949. Desde muito tempo e até aquele momento, a posição de Milliet era abertamente reticente em relação à arte abstrata.

Seu texto para o catálogo da exposição é mais burocrático do que se pensa e revela muito do preconceito existente no Brasil sobre o abstracionismo. Por isso, Léon Degand teve protagonismo especial para dobrar os gostos convencionais brasileiros ${ }^{3}$. Ele fizera contato com os principais artistas abstratos que passaram pela França, especialmente os do Grupo Abstração-Criação e do grupo de Grasse, e também teve contato próximo com Michel Seuphor, pintor e especialmente crítico da arte do casal Jean Arp e Sophie Taeuber-Arp. Esses grupos foram estabelecidos na França durante o período de guerra e, como dito, constituíam oposição ao fascismo. Seus membros eram adeptos das correntes internacionais dadás e principalmente abstracionistas. No caso de Taeuber-Arp, ela havia participado inclusive nos anos iniciais de 1930 da grande exposição de arte construtiva em Lodz, na Polônia.

O interesse de Léon Degand pela arte abstrata e o conhecimento da trajetória anterior de Sophie Tauber-Arp na arte concreta estabeleceram o precedente para a possibilidade de que a pintura da artista fosse escolhida para o prêmio de aquisição na I Bienal de São Paulo em 1951, com o trabalho intitulado Triângulos, ponto sobre ponto, retângulo, quadrados, barras, pintura a óleo sobre tela, dimensões $81 \mathrm{x}$ $65 \mathrm{~cm}$ [fig. 1]. Ele contém no verso um selo de Meudon, correspondente à classificação geral das obras de Sophie Taeuber-Arp, 1931/5. Ainda que os artistas caminhassem, em 1951, para a ruptura com as classificações tradicionais da produção artística, a própria Bienal, naquela ocasião, na contracorrente, defendia nos regulamentos de premiação a pintura como lugar hierárquico e privilegiado nas escolhas artísticas.

A separação prevalente entre a pintura e outros meios de expressão artística (escultura, gravura, desenho etc.) é algo que marcou contraditoriamente as exposições de arte abstrata e concreta naquele período no Brasil. Basta ver o caso da recepção da obra de Abraham Palatnik, com seu Aparelho Cinecromático, que foi muito elogiado por Mário Pedrosa, mas não se enquadrava formalmente nas categorias artísticas da Bienal de São Paulo4. Isso explica também porque 0 adesismo a uma concepção de arte que fosse utilitária não tinha muita permeabilidade na cena brasileira. Por paradoxal que isso pareça, em se tratando de arte concreta, essa separação tentou ser superada apenas pelo grupo paulista, que obteve pequeno sucesso na época e pouca inserção em gama mais ampla de processos produtivos. Deve-se notar que mesmo a sala especial dedicada à arte construtiva de Sophie Taeuber-Arp na Bienal de 1955 não apresentava vestidos e objetos decorativos por ela produzidos. 0 que evidencia que a própria Bienal de São Paulo também foi compreendida dentro da separação tradicional entre artes maiores e artes menores. 


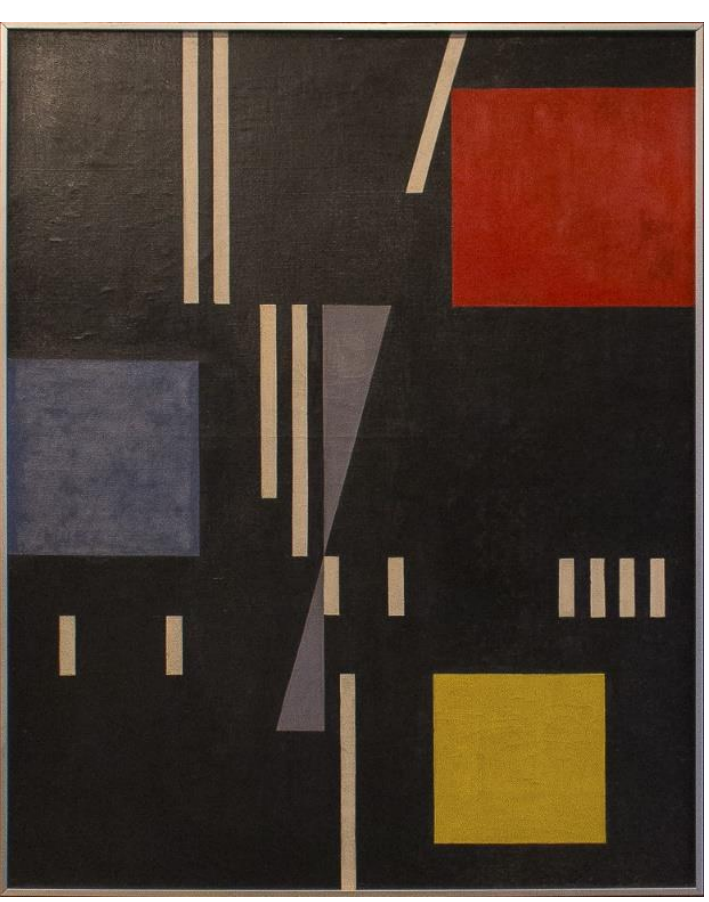

Fig.1. Sophie Taeuber-Arp, Triângulos, ponto sobre ponto, retângulo, quadrados, barras, pintura a óleo sobre tela, 1931, dimensões $81 \times 65 \mathrm{~cm}$. Acervo MAC-USP. Fonte:<http://acervodigital.unesp.br/handle/unesp/381314>.

A mostra de Sophie Taeuber-Arp na III Bienal de São Paulo contou com 43 obras, entre pinturas a óleo de vários tamanhos e materiais, guaches, desenhos, construções e relevos em madeira ou material similar, mais 4 fotografias de marionetes de 1918 e um álbum de litografias, Aux Nourritures Célestes, concebido em 1941, com gravuras de Jean Arp, Sonia Delaunay e Alberto Magnelli, publicado em 1950, com tiragem de 165 exemplares. 0 álbum fazia evidente referência à obra de André Gide e revelava 0 trabalho intenso dos artistas no período da guerra, em que o Grupo de Grasse e outras agremiações de artistas modernos se organizavam e produziam nos territórios livres da França sob ocupação nazista. A produção do trabalho coletivo Nouritures Célestes reforçava a preocupação do grupo com novos conceitos para a arte, inclusive a ideia de atividade coletiva, embora todos os trabalhos fossem individualizados, mas com inter-relações profícuas no teste de expressão comum. Longe de pressões de mercado pela exigência de autoria, os artistas desse grupo, que unia abstratos, concretos, figurativos oníricos e dadás, testaram o limite da produção para além dos cânones estabelecidos nas ideias românticas de autoria e de obra de arte original. As colaborações entre esses artistas sobrepujaram a guerra e deixaram frutos na vanguarda artística francesa e suíça, que é por onde eles puderam transitar, uma espécie de comportamento sem destino final estabelecido, em atitude nômade durante o período da guerra mundial.

Jean Arp e Taeuber-Arp hospedavam-se com frequência na casa do jovem artista e arquiteto Max Bill em Zurique. Foi lá que, depois de refazer por muitas vezes o caminho entre a Costa Azul na França e as cidades da Suíça, Taeuber-Arp faleceu. $O$ que ficou das experiências conjuntas do casal Arp foi justamente uma abertura não sectária para experiências que rompiam com rótulos de artista dadaísta ou artista concreto. Ambas as práticas eram possíveis. Ocorre que, depois da Guerra, Jean Arp será conhecido como o tipo de artista moderno que teve trajetória prioritária e particularmente ligada à experiência dadaísta. Essa visão do conjunto de sua obra foi construída pela recepção crítica norte- 
americana e pelas exposições realizadas nos Estados Unidos, particularmente no MoMA de Nova York, nos anos de 1950.

O empenho de Jean Arp foi, com iniciativa conjunta da Embaixada de Suiç̧a, de realizar exposição na Bienal de São Paulo em homenagem à Sophie Taeuber-Arp que contasse com parte significativa da produção da artista suiça e lançasse maior reconhecimento internacional de suas obras. Esta foi verdadeiramente a primeira grande exposição do conjunto das obras de Taeuber-Arp após sua morte em 1943, reunindo trabalhos de diferentes fases de sua trajetória multifacetada. Até recentemente a sala especial de Taeuber-Arp na Bienal não tinha encontrado par nos eventos, nos grandes museus e nas instituições de arte no mundo. Somente em 1981, no contexto das lutas feministas, o MoMA organizou exposição extensiva da obra de Sophie Taeuber-Arp.

Na época, a exposição de artistas suiços foi bem recebida pelos jornais locais, como se pode verificar neste artigo de Geraldo Ferraz, publicado em O Estado de São Paulo, por ocasião da abertura da Bienal de 1951, onde ele comentava mais exatamente a produção de Sonia Delaunay e de Sophie TaeuberArp para a arte abstrata. Ferraz concluía o texto expondo a importância de Sonia Delaunay na inauguração de via da arte moderna com as pesquisas abstratas e classificava Taeuber-Arp como segunda geração do abstracionismo. Diz Ferraz:

(...) apesar de sua contribuição importante para o abstracionismo, ela (Taeuber-Arp) era a segunda geração da tendência abstrata. Chegou ao abstracionismo quando todos os fatores lógicos da composição melódica e rítmica já haviam sido ordenados e estabelecidos pelas pesquisas de Robert e Sonia Delaunay, Mondrian, Doesburg e Arp (Ferraz, 1955: s/p.).

Apesar do tom de oposição entre a geração primeira e a segunda de consolidação de caminhos já desbravados na afirmação de Ferraz, está claro que Taeuber-Arp teve o mérito de produzir muito cedo arte a partir de exercícios, de depuração formal, poucas vezes vistos em outros artistas. 0 crítico brasileiro cometeu equívoco em sua apreciação, pois naquela época (década de 1950) já era de conhecimento geral que o trabalho de Sophie Taeuber-Arp contribuíra no sentido de estabelecer as primeiras bases para a arte concreta com pesquisas de forma e de cor. Como reforçaria Heinz Keller, no catálogo produzido pela representação suíça para a sala especial de Sophie Taeuber-Arp na III Bienal, em 1955, além de ser a grande exposição individual da artista até aquele momento, a artista tinha papel fundamental para a inauguração das pesquisas do concretismo nas artes visuais e esse papel era reconhecido no Brasil, por isso:

(...) foi com grande satisfação que a Suíça aceitou o convite para apresentar pela segunda vez - e com a ênfase que não foi possível na primeira Bienal de São Paulo - o trabalho de Sophie Taeuber-Arp. Não é apenas sua participação no Dada de Zurique, o que torna essa extraordinária mulher uma das pioneiras da arte moderna, já em 1916 - em um paralelo surpreendente, mas independente do grupo "Stijl" - ela ataca os problemas da arte concreta. Sua pintura e trabalho gráfico, bem como relevos, decorações e desenhos de muralhas para os tecidos, são a expressão de uma personalidade sempre criativa, intensamente clara e harmoniosa (Catálogo Suiça, 1955: 02).

Nesta exposição, seus espaços seguiram um esquema de arranjo de acordo com critérios de organização do catálogo raisonné de Sophie Taeuber-Arp, como segue: 1920-21, manchas retangulares em cores; 1916-1925, composições verticais-horizontais; 1927-1928, composições verticais-horizontais: Aubette; 1930-1939, composições estáticas com círculos, quadrados e retângulos; 1931-1934, composições dinâmicas; 1932-1939, composições com múltiplos espaços; 1933-1939, composições com elementos simétricos e assimétricos; 1936-1938, composições dentro de um círculo; 
1935-1939, relevos; 1938-1942, linhas; 1942, últimas construções. Faziam parte da exposição, uma série de fotografias de Aubette e, como já mencionado, o álbum de litografias Aux Nourritures Célestes", edição de 1950.

Em 11 de outubro de 1954, o Departamento Federal do Interior da Suíça enviou uma carta ao presidente da Bienal de São Paulo, o empresário Francisco Matarazzo Sobrinho, anunciando a representação suíça na III Bienal de 1955, após a ausência em 1953: "Senhor Presidente, temos a honra de nos referir à correspondência que trocamos com você sobre o tema da participação da Suiça na III Bienal (...) e depois anunciar que a exposição retrospectiva de Sophie Taeuber-Arp foi proposta pelo Departamento Suíço" (DFIS, 1958: 01).

Talvez a exposição de Sophie Taeuber-Arp tenha sido executada a partir de uma sugestão de Jean Arp ou Heinz Keller, e de acordo com as expectativas dos organizadores brasileiros que desejavam um pintor que representasse o abstracionismo suíço. Sem dúvida, Taeuber-Arp era muito mais do que uma mera artista abstracionista do período de entreguerras e da Segunda Guerra Mundial, ela foi uma das primeiras artistas a desenvolver linguagem de forma e de cor articuladas em sistema novo, que seria denominado de arte concreta. Jean Arp se empenhou muito para que a mostra ocorresse, em favor da memória de Taeuber-Arp. 0 documento do Departamento Federal do Interior da Suíça afirma:

De acordo com nossa proposta, na carta de 02 de outubro, para participar oficialmente novamente nesta exposição, confiamos a nosso departamento a tarefa de organizar a participação do nosso país. De acordo com o desejo expresso pelo Brasil, antecipamos uma retrospectiva de Sophie Taeuber-Arp, à qual será adicionada uma coleção de estampas e desenhos de um ou vários artistas suíços contemporâneos (DFIS, 1958: 01).

Em carta datada de 26 de outubro de 1954, Francisco Matarazzo Sobrinho escreveu ao embaixador brasileiro na Suíça, Raul Bopp, em Berna, comentando o fato de o país ter decidido, após estar ausente na II Bienal, enviar uma retrospectiva dedicada ao trabalho de Sophie Taeuber-Arp:

É com grande satisfação que me endereço ao meu querido amigo - quem acaba de nos comunicar a ambiciosa participação suíça na terceira Bienal, com uma sala dedicada ao trabalho de Sophie Taeuber-Arp - para expressar nossa sincera gratidão pelo sucesso alcançado (Matarazzo Sobrinho, 1954: 01).

Certamente, Matarazzo Sobrinho ficou feliz com a grande exposição da artista suíça, pois havia adquirido na I Bienal de 1951, como dissemos, uma obra significativa da pintora, a partir de prêmioaquisição do Banco Nacional Imobiliário [fig. 1]. Embora não exista um registro fotográfico oficial da sala especial de Taeuber-Arp na III Bienal, a lista de trabalhos no catálogo oficial, confeccionado pela Suíça, comprova a exposição de Dois círculos, planos e cruzes, 1931/16, de dimensões 55 X 46 cm, cujo original pertence ao Museu de Arte de Lodz, na Polônia. Esta pintura foi doada, juntamente com outras duas composições, no ano de 1931, por ocasião da realização de uma grande exposição construtivista internacional para o museu de Lodz. Durante sua exposição na III Bienal, a pintura 1931/16 foi apresentada em outra disposição em relação àquela adotada para exposição em Lodz [fig. 2] $]^{5}$ A diferença de disposição e de título da obra em parte se explica pela guerra na Europa ${ }^{6}$ [fig. 3]. 


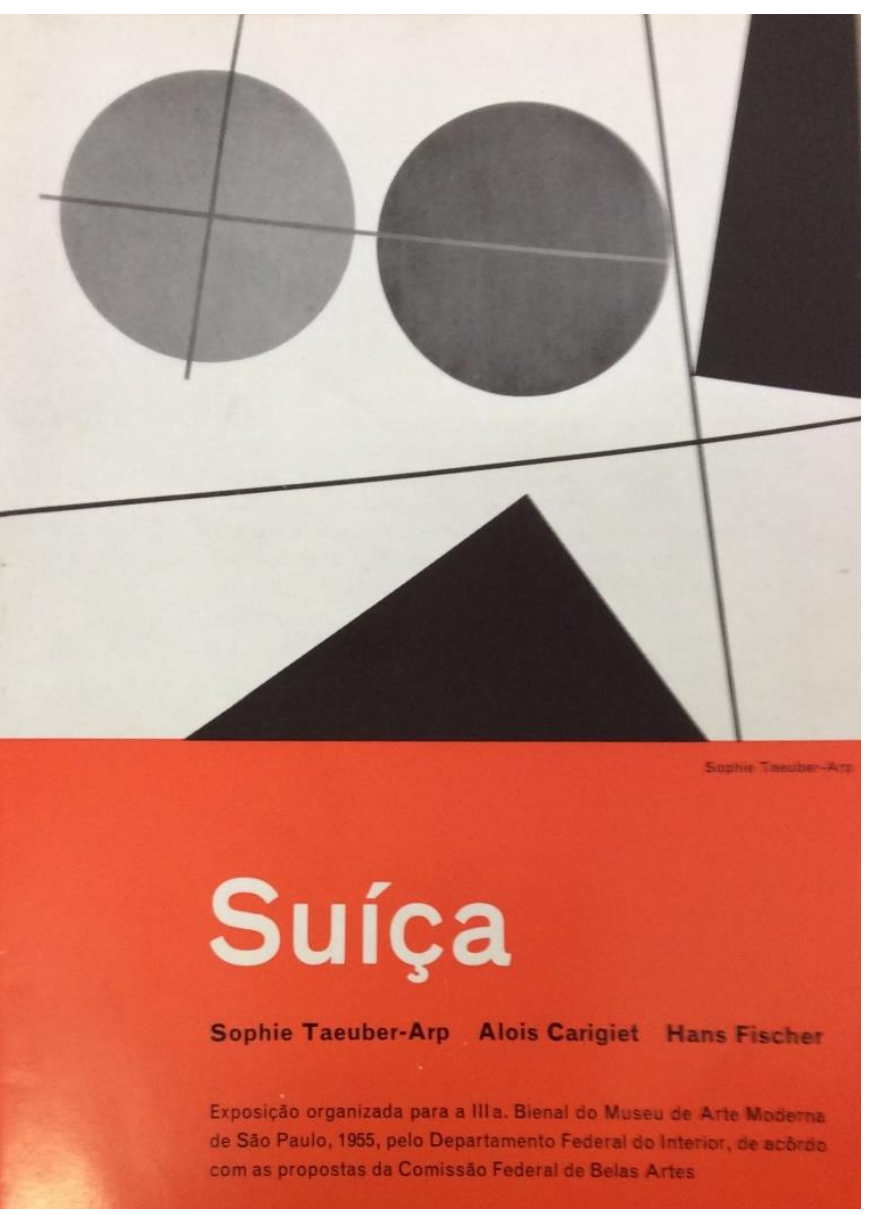

Fig.2. Capa de Catálogo Suiça com reprodução da obra Dois círculos, planos e cruzes de Sophie Taeuber Arp, 1931/16.

Acervo do autor.

As duas outras composições supracitadas são Composição vertical com círculos, quadrados e retângulos, 1930, classificação 1930/9, e Composição (Kompozycja), do ano de 1931, não identificada, com medidas de tamanho de 30 × 23cm [fig. 4]. A pintura de 1930/9 talvez não tenha participado da exposição da Bienal em 1955 (ainda que haja no verso da tela inscrição a lápis "MAM"), mas é um caso interessante de como Jean Arp lidou com a ausência de algumas obras que considerou essenciais para a exposição do trabalho de Sophie Taeuber-Arp. No ano de 1954, Arp determinou a reprodução do trabalho de Taeuber-Arp para exposições na Europa e em outras partes do mundo. 0 que se sabe é que a pintura de classificação de Sophie Taeuber-Arp 1930/9 foi reproduzida, de acordo com instruções de Jean Arp, por Marcel Schneider (Kuthy, 1988/1989: 181). Como pode ser lido em inscrição na parte de trás da imagem feita e assinada pela segunda esposa de Arp, Marguerite Hagenbach: "Esta não é uma imagem original de Sophie Taeuber-Arp, mas uma réplica (...) feita por Jean Arp, devido ao fato de que 0 original tinha sido (ilegível) feito antes da guerra. O original está no Museu de Lodz, na Polônia"7. 


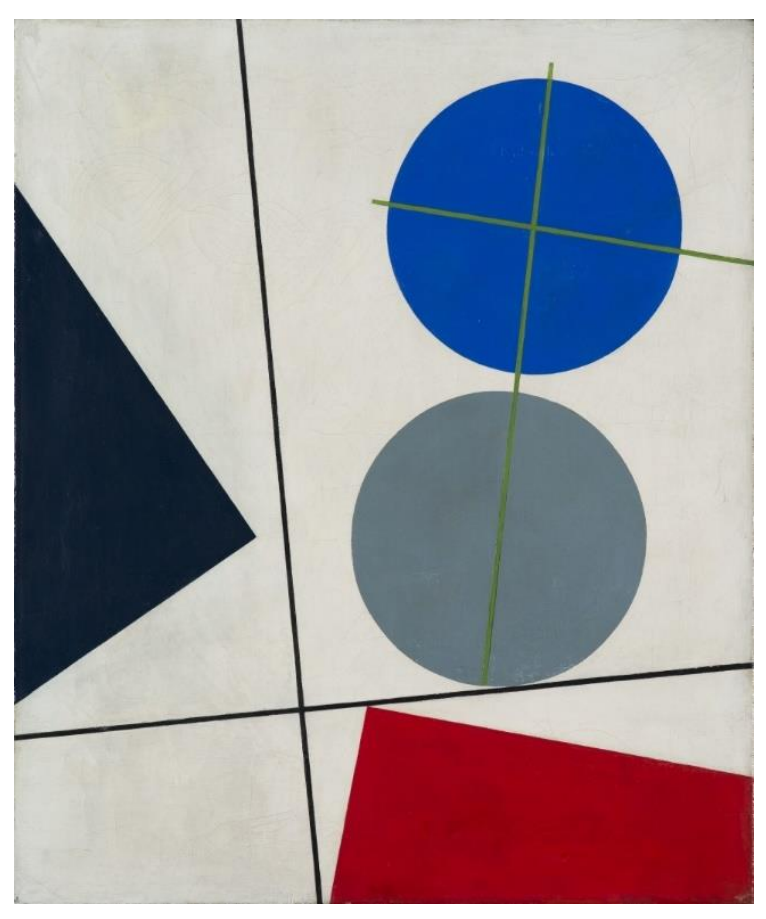

Fig.3.Sophie Taeuber Arp, Kompozycja, 1931, óleo sobre tela. Acervo Museu de Arte de Lodz. Fonte: <https://commons.wikimedia.org/wiki/ File:Sophie_Taeuber-Arp_-_Kompozycja.jpg>.

\section{ms}

ul. Więckowskiego 36, 90-734 Łódż

Tel. $(004842) 6339790$

Wykaz obiektów

\begin{tabular}{l|l|l|l|}
\hline MS/SN/M/18 & Sztuka Nowoczesna / Malarstwo Nowoczesne \\
Kompozycja \\
Taeuber-Arp, Sophie; Szwajcaria; 1931 r.; wys. $55 \mathrm{~cm}$, szer. $46 \mathrm{~cm}$; \\
malarstwo olejne; płótno, farby olejne, tempera; malarstwo
\end{tabular}

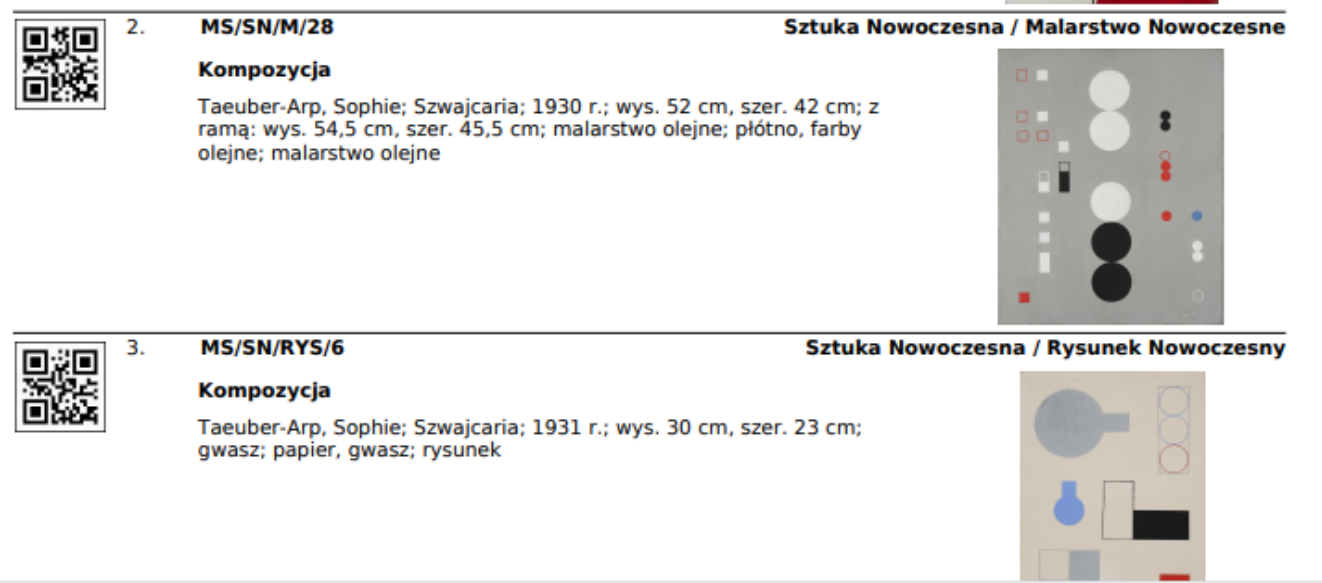

Fig. 4. Página de catálogo com lista de obras de Sophie Taeuber Arp, Museu de Lodz. Material cedido por Paulina Kurc Maj. 
A cópia da pintura de 1930/9, hoje pertencente à coleção da Fundação Arp em Berlim, foi feita por Schneider, que provavelmente usou como modelo uma fotografia ou outra reprodução em preto e branco, talvez o modelo fosse até a imagem reproduzida no catálogo de Sophie Taeuber-Arp em 1948. $\mathrm{Na}$ cópia de Schneider, as cores originais foram suprimidas, que eram, além das sombras de cinza, pretos e brancos, azul claro e vermelho. Isso, sem dúvida, deu uma aparência mais austera à pintura, permitindo ver apenas a dinâmica preocupada com a configuração da forma e não com a cor. Essa compreensão da cor como um dado subjetivo na arte concreta torna-se um álibi para a supressão de cor em muitos exercícios formais de Gestalt. Mas esse não era o caso na pintura reproduzida por Schneider.

Sandor Kuthy, em seu artigo "Nachschöpfungen"8, termo que deve ser traduzido por Recriações, discorre sobre a autoria de algumas obras de Sophie Taeuber-Arp, que foram reproduzidas por Jean Arp e apresentadas em exposições como a Bienal de São Paulo:

\begin{abstract}
1954: as cópias foram provavelmente feitas neste ano a partir de duas pinturas de Sophie Taeuber dos anos 1930 e 1931. Como (Hans) Arp não forneceu detalhes precisos da obra existente no Museu de Arte de Lodz (Polônia) desde 1931, as recriações foram feitas a partir de fotografia das obras do catálogo de Lodz e diferem nas dimensões e cores das originais. Os originais de Lodz estão elencados na lista de obras de Sophie feita por Hugo Weber em 1948: a pintura de código 1931/16 consta ali. (Hans) Arp apresentou a cópia de Dois círculos planos e cruzes na Bienal de São Paulo, em 1955, a partir da obra original de Sophie Taeuber ${ }^{9}$ (Kuthy, 1988: 181).
\end{abstract}

A imagem da obra 1931/16 foi publicada em uma seção especial da revista O Cruzeiro que fora dedicada à Bienal de São Paulo, juntamente com a reprodução de Doze espaços com planos, tiras angulares e blocos circulares, com número de classificação 1939/3. Essas imagens foram reproduzidas em orientação espacial diversa de suas orientações originalmente estabelecidas; 0 que precisa ser dito é que além de haver dificuldades inerentes à apresentação de obras reconstituídas de Taeuber-Arp, parecia haver dificuldade, difundida em nosso ambiente cultural, para entender a percepção ou a orientação espacial em uma pintura abstrata ou concreta. Contudo, isso também foi verificado no catálogo de Lodz. Havia também, na página da revista O Cruzeiro, a reprodução de dois retratos famosos da fase dadaísta de Taeuber-Arp de 1918 e outro menos conhecido, provavelmente tirado na França de 1940.

O texto padrão de Jean Arp sobre a obra de arte de Sophie Taeuber-Arp, que foi publicado no catálogo da representação suíça para a III Bienal ${ }^{10} \mathrm{e}$ em muitos jornais, chama a atenção para 0 uso de cores básicas em suas pinturas da década de 1930, mas não serve como uma indicação para Dois círculos, planos e cruzes, 1931/16. Diz Jean Arp:

Por volta de 1930, ela adotou um modo de composição por retângulos e quadrados em fundo monocromático, preto ou branco. Às vezes ela introduz triângulos e círculos. Ela geralmente une essas figuras com linhas retas e as anima, nessas profundidades brancas ou pretas, com um movimento de subida, queda, oscilação ou as mantém imóveis ali. Sua paleta não contém nada, exceto azul, vermelho, amarelo, verde. Ela projeta seus trabalhos em dimensões maiores e os executa em óleo. (...) Algumas obras desse período às vezes contêm quatro ou cinco composições diferentes emaranhadas umas nas outras. Essas telas também são compostas em um único fundo preto ou branco. Ela pinta o tabuleiro de damas da noite. Esferas brancas, vermelhas e verdes servem como peões à noite. A noite brinca com o visível e o invisível. O invisível vence o visível11 (Catálogo Suíça, 1955: 0304). 
Embora o texto de Jean Arp e toda a documentação oficial da representação suíça sejam muito cuidadosos, esse material não menciona, para a informação do público, o fato de que uma cópia de uma obra de arte foi apresentada para a compreensão da trajetória da artista suíça, nem os motivos. 0 fato é que Arp considerou essas pinturas a partir da década de 1930 como uma etapa muito importante na carreira da artista, mas essa falta de informações sobre a exibição de cópias na III Bienal de São Paulo, pintadas por Schneider ou por outros pintores, para a retrospectiva de Sophie Taeuber-Arp é de fato estranha. Isso é ainda mais surpreendente quando verificamos que essas obras foram postas à venda, como pinturas da própria Taeuber-Arp, pelo próprio Jean Arp durante a III Bienal.

Outro caso de obra de arte "recriada" por Jean Arp (para usar o termo Sandor Kuthy), que foi exibida na Bienal de São Paulo de 1955, e é descrita na documentação suiça como parte da seção de composições verticais e horizontais feitas por Sophie Taeuber-Arp entre 1916 e 1925, é a Composição Simétrica - modelo, 1922, óleo em pavatex, $67,3 \times 77,5 \mathrm{~cm}$. No entanto, antes de participar da Bienal de São Paulo, essa obra havia sido exibida na Alemanha em uma exposição itinerante realizada nas cidades de Hannover, Berlim e Freiburg, em Brisgau, sobre a qual foi publicado um pequeno catálogo do Kestner Gesellschaft de Hannover. Neste catálogo foi registrada a informação, em pequenas letras abaixo do título do trabalho, de que o trabalho Composição Vertical-Horizontal foi uma réplica feita a partir de permissão de Jean Arp. Talvez tudo isso seja resultado de controvérsias de avaliação sobre os trabalhos de Taeuber-Arp, que deve ser averiguado nas correspondências disponíveis na Fundação Arp e de Sophie Taeuber-Arp.

No pequeno catálogo da exposição Jean Arp/Sophie Taeuber-Arp, realizada entre 07 de janeiro e 13 de fevereiro de 1955 em Hannover, encontramos uma informação de que um dos relevos verticais de Sophie Taeuber-Arp foi assim elaborado: "Execução de um desenho de Sophie Taeuber-Arp de 1922, óleo / madeira, $67 \times 77 \mathrm{~cm}$, supervisionado por Jean Arp"12. Deve-se dizer que o texto deste catálogo relativo a Jean Arp foi escrito por Alfred Hentzen e o texto sobre Sophie Taeuber-Arp, de Georg Schmidt. $O$ texto de Hentzen enfatizou a conexão entre a nova arquitetura e os trabalhos realizados e adquiridos para a Universidade de Caracas na Venezuela. Embora Jean Arp tivesse ganhado um prêmio de escultura na Bienal de Veneza de 1954 e não tivesse poupado esforços para a comercialização de suas obras ou de Sophie Taeuber-Arp em Hannover, na Galeria Springer em Berlim e em Freiburg, nenhuma das obras foi vendida.

A situação financeira de Jean Arp era sofrível nos idos de 1950. Para Arp, seu mercado parecia estar nesse momento no continente americano: Estados Unidos, Venezuela e por que não o Brasil? Claro, 0 Brasil. Desde o início dos anos de 1950, principalmente depois da abertura da Bienal de São Paulo, nosso país tornava-se um novo centro de negociação e compra de obras de arte moderna. Isso se deve, por um lado, ao fato de uma série de compras serem realizadas para os novos museus do Rio de Janeiro e principalmente de São Paulo, por outro, à constatação de que os mercados tradicionais na Europa tinham desaparecido com a guerra e ao final dela, as prioridades estarem ligadas à reconstrução do conjunto de países e não propriamente compra de obras de arte.

Foi por esse motivo que Madame Hagenbach comentou a Hentzen o desejo específico de mostrar e talvez vender obras de arte de Sophie Taeuber-Arp na Terceira Bienal de São Paulo:

Como a Bienal do Brasil mostrará um total de cinquenta obras de Sophie Taeuber, é melhor escolher entre as obras exibidas em Hannover e Berlim. Eu tenho um tríptico de Sophie Taeuber de 1918 que precisaria de restauração. Se não se importar, ficarei feliz em enviar. Além disso, estou muito feliz com sua sugestão de exibir duas obras colaborativas de mim e de Sophie Taeuber ${ }^{13}$. 
A Composição Vertical-Horizontal também aparece na correspondência entre Marguerite Hagenbach e Hernn Scherrer da Kunstalle de Basel, que foi responsável por enviar obras para a exposição de Hannover. A lista da exposição contém no total quinze peças e treze obras de Sophie Taeuber-Arp. Entre estes trabalhos consta Composição Vertical-Horizontal, a partir de 1922. Esta pintura não aparece no Catálogo Raisonné, editado por Georg Schmidt em 1948, pela Holbein-Verlag Basel. Na lista enviada por Madame Hagenbach, a seguinte informação aparece: "Composição Vertical-Horizontal (baseada em um desenho de 1922, feito por Sophie Taeuber-Arp e supervisionada por Arp), óleo em pavatex, 70 x $80 \mathrm{~cm}$, valor de venda 1000 marcos alemães"14.

A informação para venda pode ser encontrada na correspondência de Arp e esta Composição VerticalHorizontal não foi vendida. Sem dúvida, este é outro caso curioso de "recriação" de Jean Arp que não foi considerado por Sandor Kuthy no episódio da III Bienal de São Paulo. Tanto o trabalho (1931/16) como a Composição Vertical-Horizontal (intitulada na Bienal como Composição Simétrica - Protótipo) de 1922 foram colocados à venda, os preços foram, respectivamente, 15.494,50 cruzeiros (preço de venda de 3.500 francos suíços) e 6.640,50 cruzeiros (preço de venda de 1.500 francos suíços), como pode ser visto em correspondência com uma lista enviada pelo Departamento Federal do Interior do Governo da Suíça, de 18 de abril de 1955, para a organização da III Bienal de São Paulo.

O total de obras à venda na Bienal de São Paulo precisa ser estudado tanto no Archiv der Stiftung Hans Arp und Sophie Taeuber-Arp como no Arquivo da Bienal de São Paulo, mas já encontramos informações sobre outra obra atribuída a Taeuber-Arp que possivelmente foi feita por Arp e colocada à venda na Bienal de São Paulo: é Conchas (Shells), número 38, (1938/32), óleo em madeira, 88,1 x 63,2cm, totalizando preço de venda de 4.000 francos. 0 último caso curioso de recriação das obras de Sophie Taeuber-Arp por Jean Arp é precisamente um relevo apresentado para a III Bienal de São Paulo porque seu número de classificação é 1938/32. Ocorre que esta numeração não existe no Catálogo Raisonné da produção de Taeuber-Arp. 0 único relevo Shells catalogado é o número 1938/28 e há a seguinte informação no catálogo: "quatro ou cinco relevos retangulares são encontrados na América" (Schmidt, 1948: 141). Tudo sugere que Jean Arp provavelmente atribuiu este novo número para um novo relevo. Quantos relevos foram realmente feitos, ninguém sabe com certeza.

\section{Referências}

ARP, J. Sophie Taeuber-Arp: KestnerGesellschaft [Hannover, 07/01/195513/02/1955]. Hannover: Vandrey, 1955, s/p.

BALL, H. Flight Out Of Time. Berkeley: University of California Press, 1996.

BONDUKI, N. Origens da habitação social no Brasil. São Paulo: Estação Liberdade, 1999.

BONOMI, M. Lettera dal Brasile. Rivista I 4 soli - Rassegna d'arte attuale, Roma/Venezia, anno 2, n. 5, set.-out. 1955.

CARAMEL, L; THOMAS, A. Max Bill. Locarno: Pinacoteca Communale Casa Rusca; Lugano: Fidia Edizione d'Arte, 1991.
Sophie Taeuber-Arp. Milano: Galleria Narciso, 13 out. a 14 nov. 1973.

CARTA de Francisco Matarazzo Sobrinho para Raul Bopp, 26 out.1954, Arquivo Wanda Svevo, Fundação Bienal de São Paulo.

CARTA do Departamento Federal do Interior da Suiça (DFIS) para Francisco Matarazzo Sobrinho, 11 out. 1954, Arquivo Wanda Svevo, Fundação Bienal de São Paulo.

CARTA de Marguerite Hagenbach para Alfred Hentzen, 07 abr. 1955. Arquivo Stiftung Arp, Berlim.

CARTA de Marguerite Hagenbach para Hernn Scherrer, circa 1955. Arquivo Stiftung Arp, Berlim. 
CATÁLOGO III BIENAL DE SÃO PAULO. São Paulo: FBSP, 1955.

CATÁLOGO JEAN ARP, SOPHIE TAEUBERARP: Kestner-Gesellschaft [Hannover, 07 ja. ${ }^{a}$ 13 fev. 1955]. Hannover: Vandrey, 1955.

CATÁLOGO SUIÇA: Sophie Taeuber-Arp, Alois Carigiet, Hans Fischer. Berna: Departamento Federal do Interior da Suíça, Benteli S. A.1955.

DEGAND, Léon, \& Sérgio Milliet. Do figurativismo ao abstracionismo [exposição]. São Paulo: Museu de arte Moderna, 1949.

DORFLES, G. Ultime tendenze nell'arte d'oggi: dall'informale al neo-oggettuale. Milano: Feltrinelli Editore, 1999.

FERRAZ, G. Sophie Taeuber-Arp. O Estado de São Paulo, sem data. Arquivo Wanda Svevo, Fundação Bienal de São Paulo, Dossiê Sophie Taeuber-Arp, 1955.

GUILBAUT, S. Respingos na parada modernista: uma invasão da arte abstrata no Brasil, 1947-1948. ARS (São Paulo), São Paulo, v. 9, n. 18, p. 148-173, 2011. Disponível em: $<$ http://www.scielo.br/scielo.php?script=sci_artt ext\&pid=S1678-

$53202011000200010 \&$ Ing $=e n \& n r m=i s 0>$.

Acesso em: 03 mar. 2020.
GULLAR, F. Etapas da arte contemporânea: do cubismo ao neoconcretismo. São Paulo: Nobel, 1985.

HÜTTINGER, Eduard. Max Bill. Zürich: ABC Verlag, 1977.

KUTHY, S. Sophie Taeuber, Jean Arp: Künstlerpaare. Wuppertal, Berna: Kunstmuseum Bern, Stiftung Jean Arp und Sophie Taeuber-Arp, Rolandseck, Von der Heydt-Museum, 1988/1989.

LANCHNER, Carolyn. Sophie Taeuber-Arp. New York: The Museum of Modern Art, 1981.

OSÓRIO, L. C. Abraham Palatnik. São Paulo: Cosac Naify, 2004.

PEDROSA, M. As pedras de Arp. Jornal do Brasil, Rio de Janeiro, Primeiro Caderno, 27 mai., p?, 1958.

SCHMIDT, Georg; WEBER, Hugo. Sophie Taeuber-Arp. Basel: Holbein-Verlag, 1948.

SEUPHOR, Michel. L'art abstrait. Ses origines, ses premiers maitres. Paris: Maeght, 1949.

Mission spirituelle de Tart à propos de l'oeuvre de Sophie Taeuber-Arp et de Jean Arp. Paris: Berggruen, 1953.

SMITHSON, A. P. The heroic period of modern architecture. New York: Rizzoli, 1981.

Notas

\footnotetext{
* Professor do curso de Teoria, Crítica e História da Arte da Universidade de Brasília. Desenvolve pesquisa sobre arte brasileira com ênfase na história da crítica de arte no Brasil. E-mail de contato: <marcelomari.vis@gmail.com>. ORCID:<https://orcid.org/0000-00016352-9460>

${ }^{1}$ Marguerite Hagenbach tornou-se esposa de Jean Arp em 1959.

2 Para uma análise mais pormenorizada sobre os processos de modernização social e artística no Brasil (Bonduki, 1999).

3 Para estudo mais detido sobre a influência de Leon Degand no ambiente artístico brasileiro (Guilbaut, 2011).

4 Para um estudo mais pormenorizado sobre a importância da obra de Palatnik na I Bienal (Osorio, 2004).

${ }^{5}$ A disposição da pintura 1931/16, apresentada na capa do Catálogo da Suiça (feito especialmente para suplementar informações do Catálogo da Bienal de São Paulo) dá a entender que a obra fora exposta em posição diversa daquela adotada pelo Museu de Lodz, Polônia, como pode se ver na figura 4.

${ }^{6}$ A obra intitulada Dois círculos, planos e cruzes, 1931/16, será renomeada pelo Museu de Lodz como Composição, não havendo registro de atribução desse nome pela própria artista Sophie Taeuber-Arp ou coisa parecida. Não existe também nenhuma documentação sobre o empréstimo dessa obra para exposição na Bienal de São Paulo.

7 Inscrição no verso do quadro 1930/9.

${ }^{8}$ Kuthy define o que é Recriação para Arp: "Quando Arp parte de uma obra de Sophie Taeuber, ocasionalmente qualifica o resultado obtido como uma recriação. Esse procedimento particular, adotado após a morte da Sophie Taeuber, consistiu para ele na escolha de uma obra antiga de sua esposa, na determinação do conceito, ou seja, na intensificação, no desenvolvimento até a obtenção de uma nova forma, cuja realização confiou a um de seus praticantes. Este novo trabalho continua a ser, para Arp, um trabalho de sua falecida esposa" (Kuthy, 1988/1989: 179).

${ }^{9}$ Tradução do original: "1954: In diesem Jahr dürften die Kopien nach zwei gemälden von Sophie Taeuber aus den jahren 1930 bzw. 1931 entstanden sein. Da Arp von diesen seit 1931 im Kunstmuseum Lodz (Polónia) hängenden bildern keine genauen angaben hatte, weichen morre Wiederholungen in den massen wie in den farben von den originalen ab. Em dem unter der leitung von Jean Arp durch Hugo Weber 1948 erstellten verzeichnis der werke Sophie Taeubers sind die originale von Lodz aufgeführt: abgebildet ist das gemälde
} 
von 1931/16. Arp zeigte 1955 an der Biennale von São Paulo die kopie von Zwei flache kreise und kreuze, 1931 /16, al sein originalwerk von Sophie Taeuber".

10 Trata-se de catálogo confeccionado pela representação suiça e servia como suplemento do Catálogo da Bienal de São Paulo.

11 Tradução do original: "Vers 1930, elle adopte un mode de composition par rectangles et carrés sur un fond unicolore, noir ou blanc.

Parfois elle y introduit des triangles et des cercles. Elle joint souvent ces figures entre elles par des lignes droites et les anime, sur ces profondeurs blanches ou noires, d'un mouvement d'ascension, de chute, d'oscillation, ou les y maintient immobiles. Sa palette ne connait guère que le bleu, le rouge, le jaune, le vert. Elle conçoit ses oeuvres dans de plus grandes dimensions, et les exécute à huile. (...) Quelques oeuvres de cette époque contiennent parfois quatre ou cinq compositions diferentes enchevêtrées les unes dans autres. Ces toiles sont également composées sur um fond unicolore noir ou blanc. Elle peint le damier de la nuit. Des sphères blanches, rouges, vertes, servent de pions à la nuit. La nuit joue avec le visible et l'invisible. L'invisible bat le visible".

12 Tradução do original: Von Jean Arp überwachte ausführung einer werkzeichnung von Sophie Taeuber aus dem jahr 1922, öl / holz, 67x77cm" (Arp, 1955: s/p).

${ }^{13}$ Tradução do original: "Da die Biennale in Brasilien eine gesamtschau von fünfzig arbaiten von Sophie Taeuber zeigen wird, ist es das beste, aus den in Hannover und Berlin ausgestellten werken zu wählen. Ich besitze ein Triptycon von Sophie Taeuber aus dem jahre 1918, welches der restauration bedürftig wäre. Falls sie dies nicht stört, werde ich es gerne schicken. Ausserdem ist mir ihr vorschlag sehr recht, zwei gemeinschaftsarbeiten von Sophie Taeuber und mir auszustellen", cf. Carta de Marguerite Hagenbach para Alfred Hentze, 07 abr.1955. Pertencente ao acervo do Archiv der Stiftung Jean Arp und Sophie Taeuber-Arp.

${ }^{14}$ Carta de Marguerite Hagenbach para Hernn Scherrer, sem data precisa, provavelmente do mês de julho de 1955.

Artigo recebido em janeiro de 2020. Aprovado em março de 2020. 